\title{
Analysis on the influence of water concentration on ADCP current measurement
}

\author{
Mingmin $\mathrm{ZHANG}^{1, *}$, Yicheng $\mathrm{LIU}^{1}$, Jinghan $\mathrm{XU}^{2}$, and Hui ZHAO ${ }^{1}$ \\ ${ }^{1}$ Tianjin Research Institute for Water Transport Engineering, M.O.T., Tianjin, 300456, China \\ ${ }^{2}$ Tianjin Dongfang Tairui Technology CO., LTD, Tianjin, 300456, China
}

\begin{abstract}
With the objective of improving the measure performance of Acoustic Doppler Current Profiler (ADCP) and promoting the level of marine environmental monitoring, the precision and accuracy of ADCP current measurement have been analyzed in detail based on the current flume with water concentration ( 0 20) $\mathrm{kg} / \mathrm{m}^{3}$. The experiments indicated that the precision of ADCP current measurement is enhanced with the uprising of water concentration. The precision of ADCP measurement was significantly influenced by the water concentration when the current was $(0.7-0.9) \mathrm{m} / \mathrm{s}$, and it was less affected by the water concentration when the current was $0.3 \mathrm{~m} / \mathrm{s}$. In addition, with the increase of water concentration, the accuracy of ADCP measurement increased at first and then decreased. The accuracy of current measurement was higher when the concentration was $(9-11) \mathrm{kg} / \mathrm{m}^{3}$, and decreased in varying degrees outside this range. When the current was $1.1 \mathrm{~m} / \mathrm{s}$, the accuracy of ADCP was greatly affected by the concentration, while it was less affected by the concentration in the case that current is $0.3 \mathrm{~m} / \mathrm{s}$. The correlation analysis and conclusion can provide a reference not only for the research and development of ocean observation equipment, but also for marine scientific studies.
\end{abstract}

\section{Introduction}

Acoustic Doppler Current Profiler (ADCP) is a kind of acoustic instrument, which uses acoustic Doppler principle to measure the frequency shift information of scattered signal in layered water medium, and uses vector synthesis method to obtain the velocity of stratified water flow in vertical section[1]. With its advantages of high measuring accuracy, plentiful measuring points, strong adaptability and high automation, ADCP has been widely used in water transportation engineering, hydrological monitoring, Marine environment research and other aspects.More importantly, ADCP has been designated as one of the four most advanced ocean observation instruments by the IOC (International Oceanographic Commission) [2-6]. However, in practical application, the measurement results of ADCP are greatly affected by environmental factors such as depth, temperature, salinity, concentration, etc., often resulting in the absence or failure of measurement data, which brings great loss of human and financial resources to the marine survey work [7-10]. In order to ensure the precision and accuracy of ADCP measurement results, some scholars have conducted relevant studies. Among them, Yan Song et al. compared the ADCP's Current Measurements in the mixing of suspended particulate matter and clear water, founded that the current measurement data is more stable after mixing an appropriate amount of suspended particulate matter [11]. Wagner $\mathrm{C} R$ showed that the navigation ADCP could not be used under the condition of too shallow water [12].
The WHS600-I ADCP manufactured by Teledyne RD Instrument in the United States and the Aquadopp Profiler $2 \mathrm{MHz}$ ADCP manufactured by Nortek in Norway are selected herein as the prototype to comprehensively analyze the characteristics of the accuracy and precision of the ADCP current measurements in the water environment with a concentration of $(0-20) \mathrm{kg} / \mathrm{m}^{3}$. The analysis and conclusion of this study are not only of great value to the development and application of ADCP, but also of practical significance to the standardization of the detection methods of ADCP parameters, Marine environmental protection and scientific research.

\section{Materials and methods}

\subsection{Experimental equipment and facilities}

In this paper, the experimental equipment and facilities mainly include conductivity-temperature-depth (CTD), ADCP and verification device of ADCP.

(1) The Compact-CTD is a kind of self-contained CTD that equipped with high-precision pressure, temperature, salinity and concentration sensors. Compared with traditional concentration measuring instruments, it has the advantages of higher accuracy, higher efficiency and easy operation in field measurement.

(2)The WHS600-I ADCP is manufactured by Teledyne RD Instruments in the United States, which uses acoustic doppler principle to measure the velocity and flow

*Corresponding author:2570983389@qq.com 
direction of ocean currents at different depths. TRDI's broadband signal processing technology enables the current measurement accuracy of WHS600-I ADCP to achieve $0.3 \% v \pm 0.3 \mathrm{~cm} / \mathrm{s}$ ( $v$ represents the current). In addition, the WHS600-I ADCP can be installed on buoys, ships or seabed, which makes it highly accurate for long term measurements.

(3) The AquAdopp Profiler 2MH ADCP consists of a $2 \mathrm{MHz}$ acoustic transducer and emits a short pulsed sound beam into the water. It has the characteristics of wide application range, small size and light weight, which is mainly used for nearshore Marine research, online monitoring and scientific research of rivers, lakes and rivers. The accuracy of current measurement is $1 \% \mathrm{v}$ $\pm 0.5 \mathrm{~cm} / \mathrm{s}$ ( $v$ represents the current).

(4) The verification device of ADCP (Fig. 1)mainly includes a current flume, a current trailer, a fixed support for ADCP and a suspended particle agitator, of which the size of the current flume is $75 \mathrm{~m}$ (length) $\times 1.5 \mathrm{~m}$ (width) $\times 1.5 \mathrm{~m}$ (depth), and the maximum speed of the current trailer is $2 \mathrm{~m} / \mathrm{s}$, also it is equipped with lifting and turning mechanism.

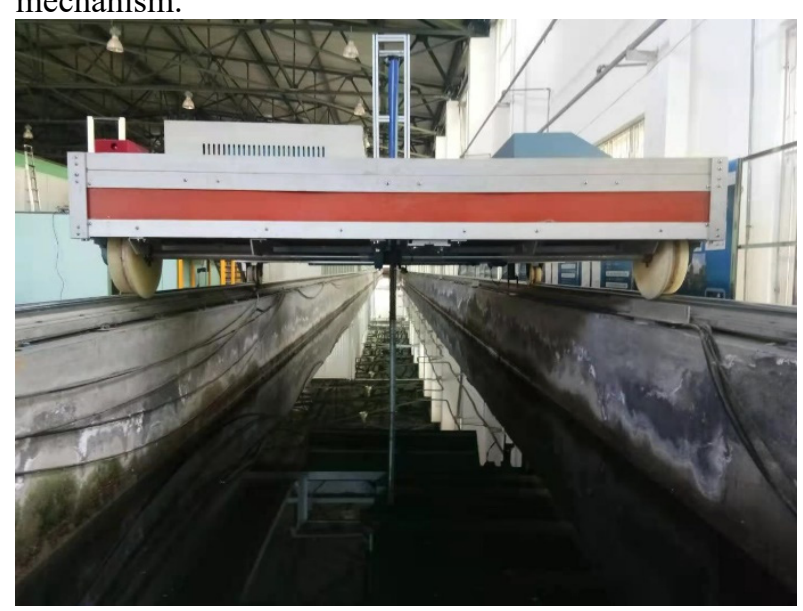

Fig. 1. Verification device of ADCP

\subsection{Experimental principle}

Two tracks are set up above the rectangular static flume with uniform cross-section, and a current trailer which can move back and forth is installed on the track. The ADCP is fixed on the current trailer by lifting measuring rod, which can rotate around the axis, so that the indicated direction of the ADCP is in the same direction with the traveling direction of the trailer. Under the condition that the water in the flume is stationary, when the ADCP is moving at different speeds on the track, it can be equivalent to the ADCP is stationary, while the water in the flume is flowing at a speed of trailer relative to the ADCP. On the premise that the speed of the current trailer is known, the current measurements of the ADCP in different water concentrations can be evaluated by analyzing the consistency between the measured velocity and the trailer speed as well as the dispersion between the measured values. The diagram of ADCP current measurement system is shown in Figure 2.

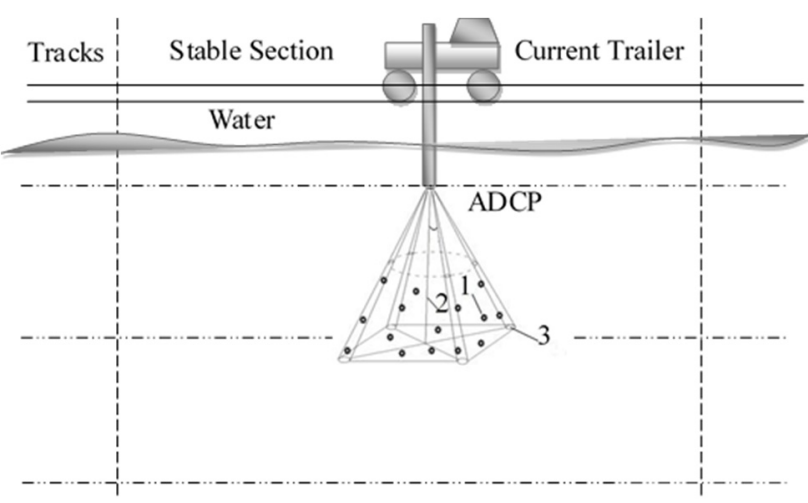

Fig. 2. The diagram of ADCP current measurement system 1-Scatterers in water; 2-Central axis; 3-Transmit beams.

\subsection{Experimental procedure}

The main purpose of this experiment is to obtain the current measurements of ADCP in the flume with different water concentration. The specific steps are as follows:

1) Start the current trailer, which drag the mixing device reciprocate several times until the suspended sediment is evenly dispersed;

2) Set up five concentration collection points $\left(N_{1}\right.$, $\left.N_{2} \ldots N_{5}\right)$ at equal intervals in the flume, and 30 concentration values at each collection point were measured with Compact-CTD;

3) Take the average of 30 measurements of CompactCTD as the actual measured value of the collection point $\bar{N}_{i}(i=1,2 、 3 、 4 、 5)$;

4) Calculate the average value of five collection points and take it as the actual concentration of the water environment;

5) Fix the ADCP to the lifting rod of current trailer, and adjust the ADCP forward through the Angle rotary plate until it is in the same direction as the current trailer. Meanwhile, adjust the lifting mechanism so that the depth of the ADCP into water is 0.4 meters;

6) Within the trailer speed range, six speed points of $0.3 \mathrm{~m} / \mathrm{s}, 0.5 \mathrm{~m} / \mathrm{s}, 0.7 \mathrm{~m} / \mathrm{s}, 0.9 \mathrm{~m} / \mathrm{s}, 1.1 \mathrm{~m} / \mathrm{s}$ and $1.3 \mathrm{~m} / \mathrm{s}$ are selected to input into the current trailer control system. At the same time, the current trailer is controlled by wireless remote control equipment to pull the ADCP at the selected speed;

7) When the current trailer runs to the stable section, record 30 currents continuously measured by ADCP;

8) Add a certain amount of fine-grained sand to the flume, and repeat steps 1) -7).

The concentration point of flume were set at $1 \mathrm{~kg} / \mathrm{m}^{3}, 3$ $\mathrm{kg} / \mathrm{m}^{3}, 5 \mathrm{~kg} / \mathrm{m}^{3}, 7 \mathrm{~kg} / \mathrm{m}^{3}, 9 \mathrm{~kg} / \mathrm{m}^{3}, 11 \mathrm{~kg} / \mathrm{m}^{3}, 13 \mathrm{~kg} / \mathrm{m}^{3}, 15$ $\mathrm{kg} / \mathrm{m}^{3}, 17 \mathrm{~kg} / \mathrm{m}^{3}$ and $19 \mathrm{~kg} / \mathrm{m}^{3}$. The actual measured values of each concentration collection point by the CTD are shown in Table 1.

Table 1. The actual measured values of each concentration collection point

\begin{tabular}{|c|c|c|c|c|c|}
\hline $\begin{array}{c}\text { Point 1 } \\
\left(\mathbf{k g} / \mathbf{m}^{\mathbf{3}}\right)\end{array}$ & $\begin{array}{c}\text { Point 2 } \\
\left(\mathbf{k g} / \mathbf{m}^{\mathbf{3}}\right)\end{array}$ & $\begin{array}{c}\text { Point 3 } \\
\left(\mathbf{k g} / \mathbf{m}^{\mathbf{3}}\right)\end{array}$ & $\begin{array}{c}\text { Point 4 } \\
\left(\mathbf{k g} / \mathbf{m}^{\mathbf{3}}\right)\end{array}$ & $\begin{array}{c}\text { Point 5 } \\
\left(\mathbf{k g} / \mathbf{m}^{\mathbf{3}}\right)\end{array}$ & $\begin{array}{c}\text { Mean } \\
\left(\mathbf{k g} / \mathbf{m}^{\mathbf{3}}\right)\end{array}$ \\
\hline 1.009 & 1.002 & 1.008 & 1.010 & 1.005 & 1.0068 \\
\hline 3.011 & 3.015 & 3.011 & 3.010 & 3.012 & 3.0118 \\
\hline 5.014 & 5.019 & 5.019 & 5.016 & 5.021 & 5.0178 \\
\hline 7.015 & 7.008 & 7.002 & 7.012 & 7.008 & 7.0090 \\
\hline 9.005 & 9.002 & 9.003 & 9.007 & 8.999 & 9.0032 \\
\hline
\end{tabular}




\begin{tabular}{|l|l|l|l|l|l|}
\hline 11.018 & 11.008 & 11.009 & 11.016 & 11.013 & 11.0128 \\
\hline 13.014 & 13.010 & 13.014 & 13.020 & 13.017 & 13.0150 \\
\hline 15.010 & 15.008 & 15.002 & 15.004 & 15.007 & 15.0062 \\
\hline 17.000 & 17.003 & 17.000 & 16.996 & 17.006 & 17.0010 \\
\hline 19.009 & 19.008 & 19.010 & 19.005 & 19.013 & 19.0090 \\
\hline
\end{tabular}

\subsection{Precision and Accuracy}

\subsubsection{Precision of current measurement}

Precision refers to "the degree of consistency between the indicated or measured values that obtained from repeated measurements of the same or similar objects under specified conditions" [13]. Precision is usually expressed in numerical terms as the degree of imprecision, such as the standard deviation, variance, or coefficient of variation under specified measurement conditions. In this paper, the experimental standard deviation $s(x)$ was estimated by Bessel formula as

$$
s(x)=\sqrt{\frac{\sum_{i=1}^{n}\left(x_{i}-\bar{x}\right)^{2}}{n-1}}
$$

Where $x_{i}$ is the measured value of the $i$ th current measurement, $\bar{x}$ is the arithmetic average of $n$ measurements, which is used to evaluate the precision of ADCP current measurement finally.

\subsubsection{Accuracy of current measurement}

Accuracy refers to "the degree of agreement between the measured value and its true value" [13]. However, truth value is an ideal concept which is generally impossible to know exactly, but it can be replaced by conventional true value. Indication error is one of the most important metrology characteristics of a measuring instrument, and its essence reflects the accuracy of the measuring instrument. The larger the absolute value of the indication error, the lower the accuracy. In this paper, the average value of $30 \mathrm{ADCP}$ current measurements is used as the measured value, and the speed of the current trailer in the stable section is used as the conventional true value. Finally, the absolute value of the indication error is used to evaluate the accuracy of the ADCP current measurement.

\section{Results and Discussion}
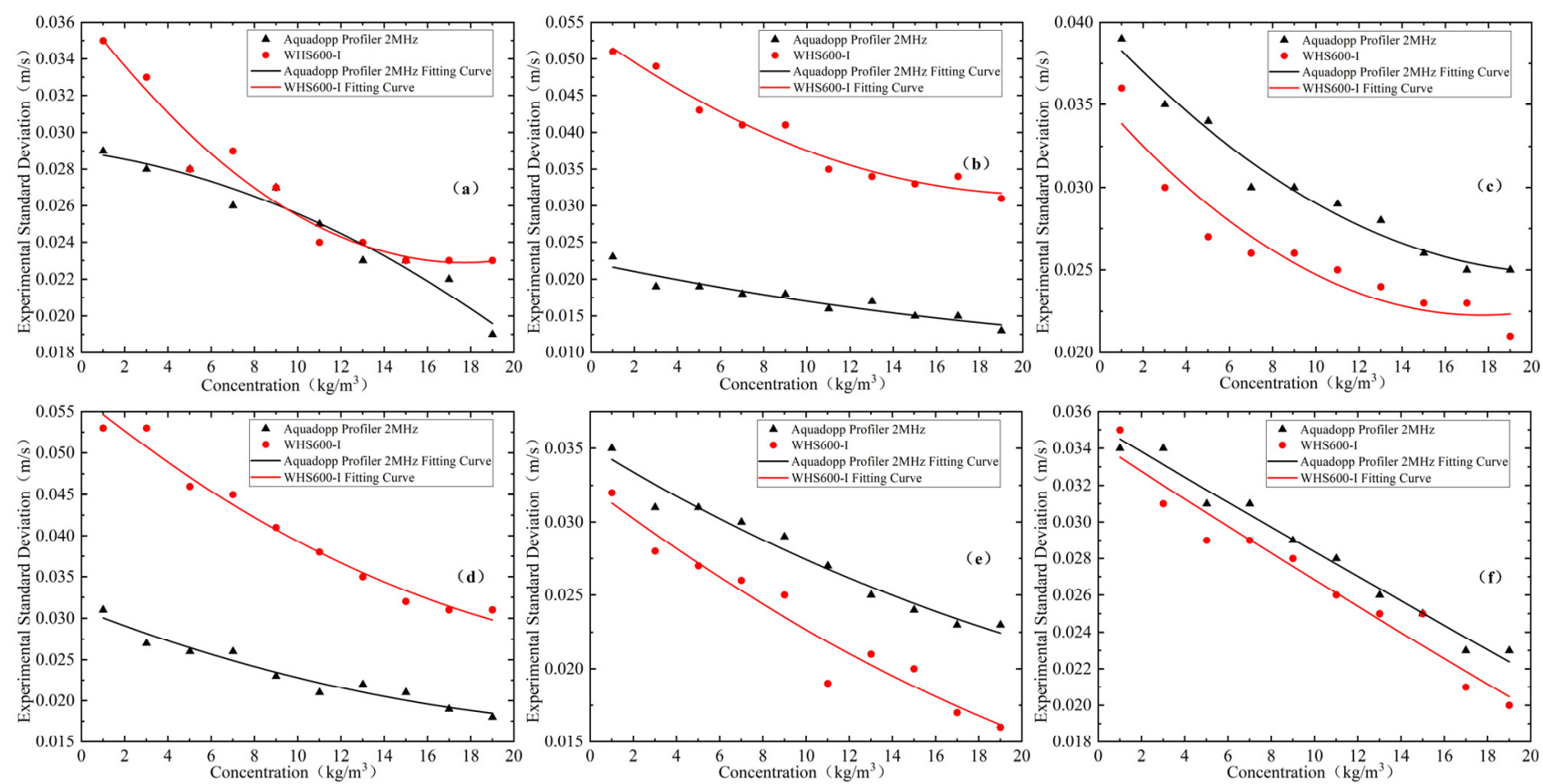

Fig. 3. The fitting curve between concentration value and experimental standard deviation of the current measurements

(a) Current:0.3m/s; (b) Current:0.5m/s; (c) Current:0.7m/s; (d) Current:0.9m/s; (e) Current:1.1m/s; (f) Current:1.3m/s.

As schematised in Fig. 3, which shows the fitting curve between concentration value and experimental standard deviation of the current measurements, the experimental standard deviation of each current measurement is less than $0.055 \mathrm{~m} / \mathrm{s}$ within the range of water concentration. The maximum experimental standard deviation of Aquadopp Profiler $2 \mathrm{MHz}$ ADCP is $0.039 \mathrm{~m} / \mathrm{s}$ (Fig. 3c) and the minimum is $0.013 \mathrm{~m} / \mathrm{s}$ (Fig. $3 \mathrm{~b}$ ), while the maximum experimental standard deviation of WHS600-I ADCP is $0.053 \mathrm{~m} / \mathrm{s}$ (Fig. 3d) and the minimum is $0.016 \mathrm{~m} / \mathrm{s}$ (Fig. 3e)

In this experiment, under the condition that the current remains unchanged, the experimental standard deviation decreases as the concentration increases, that is, the higher the concentration, the higher the measurement precision. When the current is $1.3 \mathrm{~m} / \mathrm{s}$ (Fig. $3 \mathrm{f}$ ), the precision of current measurement shows an obvious linear downward trend with the increase of concentration, while at $0.7 \mathrm{~m} / \mathrm{s}$ (Fig. 3c) and $0.9 \mathrm{~m} / \mathrm{s}$ (Fig. 3d), it shows a downward trend of quadratic curve. In addition, the precision of Aquadopp profiler $2 \mathrm{MHz}$ ADCP measurement is most affected by the water concentration when the current at $0.7 \mathrm{~m} / \mathrm{s}$ (Fig. $3 \mathrm{c}$ ), and the experimental standard deviation decreased by $0.014 \mathrm{~m} / \mathrm{s}$, from $0.039 \mathrm{~m} / \mathrm{s}$ at the water concentration of $1.007 \mathrm{~kg} / \mathrm{m}^{3}$ to $0.025 \mathrm{~m} / \mathrm{s}$ at the water concentration of $19.009 \mathrm{~kg} / \mathrm{m}^{3}$. On the other hand, the precision of Aquadopp profiler $2 \mathrm{MHz}$ ADCP measurement is the least 
affected by the water concentration when the current is $0.3 \mathrm{~m} / \mathrm{s}$ (Fig. 3a) and $0.5 \mathrm{~m} / \mathrm{s}$ (Fig. 3b), and it only decreased by $0.010 \mathrm{~m} / \mathrm{s}$. For the WHS600-I ADCP, the precision of current measurement is the most affected when current at $0.9 \mathrm{~m} / \mathrm{s}$ (Fig. 3d), which the experimental standard deviation reduced by $0.022 \mathrm{~m} / \mathrm{s}$, and it is the least affected when current is $0.3 \mathrm{~m} / \mathrm{s}$ (Fig. 3a), with a decrease of only $0.012 \mathrm{~m} / \mathrm{s}$.
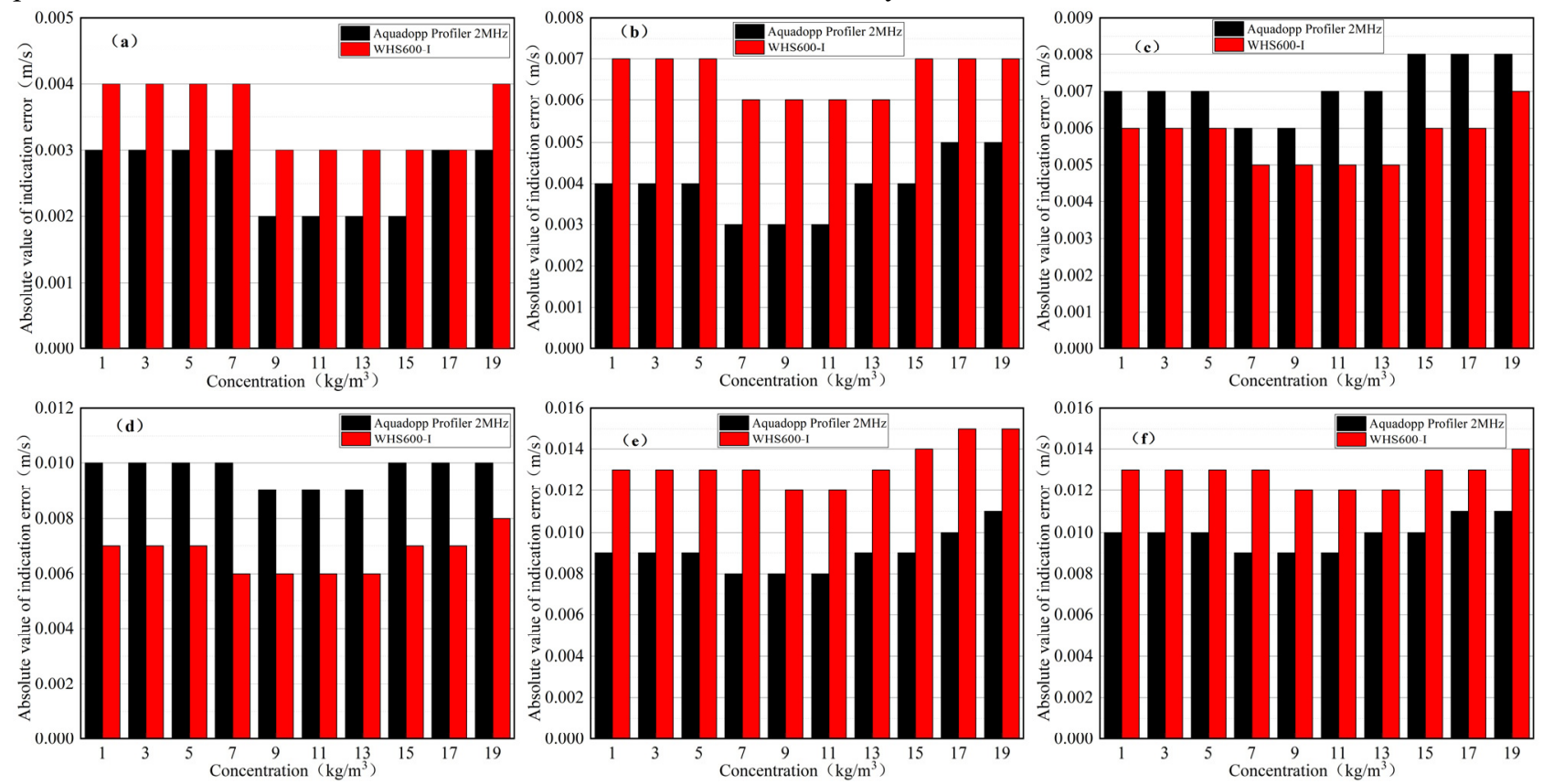

Fig. 4. The absolute value of ADCP current indication error

(a) Current:0.3m/s; (b) Current:0.5m/s; (c) Current:0.7m/s; (d) Current:0.9m/s; (e) Current:1.1m/s; (f) Current:1.3m/s.

As schematised in Fig. 4, which shows the absolute value of ADCP current indication error in each concentration, all the absolute values of the indication error are less than $0.016 \mathrm{~m} / \mathrm{s}$ within the range of water concentration. For the Aquadopp Profiler $2 \mathrm{MHz}$ ADCP, the maximum value of indication error is $0.011 \mathrm{~m} / \mathrm{s}$ (Fig. 4e,f) and the minimum is $0.002 \mathrm{~m} / \mathrm{s}$ (Fig. $4 \mathrm{a}$ ), while the maximum value of indication error of the WHS600-I ADCP is $0.015 \mathrm{~m} / \mathrm{s}$ (Fig. $4 \mathrm{e}$ ) and the minimum is $0.003 \mathrm{~m} / \mathrm{s}$ (Fig. $4 \mathrm{a}$ ).

When the concentration remains unchanged, the absolute value of the indication error shows an increasing trend as the current increases.

Under the condition of constant current, the accuracy of current measurement shows a trend of first decreasing and then increasing with the increase of concentration. The Aquadopp Profiler $2 \mathrm{MHz}$ ADCP has the smallest absolute value of the indication error when the concentration is $(9-11) \mathrm{kg} / \mathrm{m}^{3}$, especially when the current is $0.3 \mathrm{~m} / \mathrm{s}$ (Fig. $4 \mathrm{a}$ ), the absolute value of the indication error is only $0.002 \mathrm{~m} / \mathrm{s}$. When the concentration is outside (9-11) $\mathrm{kg} / \mathrm{m}^{3}$, the absolute value of indication error increases in varying degrees,such as when the current is $1.1 \mathrm{~m} / \mathrm{s}$ (Fig. 4e), the increase is most obvious, that is, it is most affected by the concentration, and the appreciation is $0.003 \mathrm{~m} / \mathrm{s}$. In addition, when the current is $0.3 \mathrm{~m} / \mathrm{s}$ (Fig. $4 \mathrm{a}$ ) and $0.9 \mathrm{~m} / \mathrm{s}$ (Fig. 4d), the absolute value of indication error is less affected by concentration with the amount of change is $0.001 \mathrm{~m} / \mathrm{s}$. For WHS600-I ADCP, as with Aquadopp Profiler $2 \mathrm{MHz}$, the absolute value of the indication error is the smallest at the concentration (9-11) $\mathrm{kg} / \mathrm{m}^{3}$, that is, the accuracy of the current measurement reaches the highest. Especially when the current is $0.3 \mathrm{~m} / \mathrm{s}$ (Fig. 4a), the absolute value of the indication error is only $0.003 \mathrm{~m} / \mathrm{s}$. When the concentration is outside $(9-11) \mathrm{kg} / \mathrm{m}^{3}$, the absolute value of indication error increases in varying degrees, such as when the current is $1.1 \mathrm{~m} / \mathrm{s}$ (Fig. $4 \mathrm{e}$ ), the accuracy of current measurement is most affected by the concentration, which increases by $0.003 \mathrm{~m} / \mathrm{s}$, while the concentration has the least influence when the current is $0.3 \mathrm{~m} / \mathrm{s}$ (Fig. $4 \mathrm{a}$ ) and $0.5 \mathrm{~m} / \mathrm{s}$ (Fig. 4b), the increment is only $0.001 \mathrm{~m} / \mathrm{s}$.

\section{Conclusions}

The WHS600-I ADCP and the Aquadopp Profiler $2 \mathrm{MHz}$ ADCP are selected herein as the prototype to comprehensively analyze the characteristics of the accuracy and precision of the ADCP current measurement in the water environment with a concentration of (0-20) $\mathrm{kg} / \mathrm{m}^{3}$. The following conclusions can be drawn from this study:

(1) Under the condition that the current remains unchanged, the precision of ADCP current measurement is enhanced with the uprising of water concentration.

(2) When the current is $1.3 \mathrm{~m} / \mathrm{s}$, the precision of current measurements shows an obvious linear downward trend with the increase of concentration, while at $0.7 \mathrm{~m} / \mathrm{s}$ and $0.9 \mathrm{~m} / \mathrm{s}$, it shows a downward trend of quadratic curve.

(3) The precision of ADCP current measurement is greatly affected by concentration when the range of current is $(0.7-0.9) \mathrm{m} / \mathrm{s}$, while the current is $0.3 \mathrm{~m} / \mathrm{s}$, it is less affected by concentration.

(4) Under the condition of constant current, the accuracy of current measurement shows a trend of first decreasing and then increasing with the increase of concentration. The absolute value of the indication error is the smallest when the concentration is $(9-11) \mathrm{kg} / \mathrm{m}^{3}$, that is, the accuracy of the current measurement reaches the 
highest. When the concentration is outside $(9-11) \mathrm{kg} / \mathrm{m}^{3}$, the accuracy of the current measurement decreases in varying degrees.

(5) When the current is $1.1 \mathrm{~m} / \mathrm{s}$, the accuracy of current measurement is most affected by the concentration, and it is least affected by the concentration when the current is $0.3 \mathrm{~m} / \mathrm{s}$.

\section{Acknowledgments}

This work was supported by National Key Research and Development Program(2018YFF0212202) and Research and Innovation Fund of Tianjin Research Institute for Water Transport Engineering, M.O.T.(TKS180104).

\section{References}

1. Y.X. Liu, Review on development of ADCP technology and its application. Hydrographic surveying and charting, 36(02): 45-49.(2016)

2. H.M. Zhang, Z.G. Chen, J.N. Zhao, ADCP integration meaurement based on external sensors. Gematics and infoemation science of wuhan university, 41(8):11311136.(2016)

3. D.A. Fong, S.G. Monismith,Evaluation of the Accuracy of a Ship-Mounted, Bottom-Tracking ADCP in a Near- Shore Coastal Flow.Journal of atmospheric and oceanic technology, 21(7):1121-1128.(2004)

4. R. Bozzano, E. Fanelli, S. Pensieri, Temporal variations of zooplankton biomass in the Ligurian Sea inferred from long time series of ADCP data. Ocean Science, 10(1):93-105.( 2014)

5. F. Claude, Y. Wang, L. Leena, Empirical modeling of spatial 3D flow characteristics using a remotecontrolled ADCP system:monitoring a spring flood. Water, 7(12):217-217.(2015)

6. H.L. Tang, H.T. Nie, J.G. Xiao, A quality contral procedure for shipboard ADCP data and its application. Advances in marine science, 38(1):153-161.(2020)

7. A. Sentchev, M. Yaremchuk, Monitoring tidal currents with a towed ADCP system. Ocean dynamics, 66(1):119-132.(2016)

8. Q.W. Zhou, S. Zhang, X.Y. Wang, Discussion on the calibration methods for acoustic doppler current profilers.Jounral of ocean technology, 35(4):3135.(2016)

9. Y.M. Zhi, J. Shao, Y.P. Tang, Discussion on driving scheme of ADCP current meter verification trailer.China measurement and test, 42(11):7983+93.(2016)

10. F. Jiang, S.H. Cheng, Y.C. Pang, Comparative analysis of in-suit ADCP key measuring performances.Hournal of ocean technology, (06): 59-64.(2020)

11. S. Yan, H. Wu, D.P. Sun, Application of acoustic doppler velocimetry in flume flow experiment. Research and exploration in laboratory, 36(5):913.(2017)

12. C.R. Wagner, D.S. Mueller, Comparison of bottomtrack to global positioning system referenced discharges measured using an acoustic Doppler current profiler. Journal of Hydrology, 401(3):250-258.(2011)

13. China metrology and testing society group, Basic knowledge and professional practice of second-level registered metrology, China quality inspection publishing, The BeiJing.(2017) 